\title{
Seasonal and mesoscale variability of oceanic transport of anthropogenic $\mathrm{CO}_{2}$
}

\author{
Z. Lachkar ${ }^{1,2}$, J. C. Orr ${ }^{1}$, and J.-C. Dutay ${ }^{1}$ \\ ${ }^{1}$ Laboratoire des Sciences du Climat et de l'Environnement (LSCE), CEA/CNRS/UVSQ/IPSL, Orme des Merisiers, \\ Gif-Sur-Yvette, Bat 712, 91191 Gif sur Yvette cedex, France \\ ${ }^{2}$ Environmental Physics, Institute of Biogeochemistry and Pollutant Dynamics, ETH Zurich, Universitätstrasse 16, 8092 \\ Zurich, Switzerland
}

Received: 13 March 2009 - Published in Biogeosciences Discuss.: 17 April 2009

Revised: 20 August 2009 - Accepted: 29 October 2009 - Published: 9 November 2009

\begin{abstract}
Estimates of the ocean's large-scale transport of anthropogenic $\mathrm{CO}_{2}$ are based on one-time hydrographic sections, but the temporal variability of this transport has not been investigated. The aim of this study is to evaluate how the seasonal and mesoscale variability affect data-based estimates of anthropogenic $\mathrm{CO}_{2}$ transport. To diagnose this variability, we made a global anthropogenic $\mathrm{CO}_{2}$ simulation using an eddy-permitting version of the coupled ocean seaice model ORCA-LIM. As for heat transport, the seasonally varying transport of anthropogenic $\mathrm{CO}_{2}$ is largest within $20^{\circ}$ of the equator and shows secondary maxima in the subtropics. Ekman transport generally drives most of the seasonal variability, but the contribution of the vertical shear becomes important near the equator and in the Southern Ocean. Mesoscale variabilty contributes to the annual-mean transport of both heat and anthropogenic $\mathrm{CO}_{2}$ with strong poleward transport in the Southern Ocean and equatorward transport in the tropics. This "rectified" eddy transport is largely baroclinic in the tropics and barotropic in the Southern Ocean due to a larger contribution from standing eddies. Our analysis revealed that most previous hydrographic estimates of meridional transport of anthropogenic $\mathrm{CO}_{2}$ are severely biased because they neglect temporal fluctuations due to nonEkman velocity variations. In each of the three major ocean basins, this bias is largest near the equator and in the high southern latitudes. In the subtropical North Atlantic, where most of the hydrographic-based estimates have been focused, this uncertainty represents up to $20 \%$ and $30 \%$ of total merid-
\end{abstract}

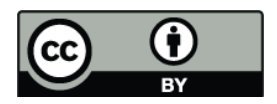

Correspondence to: Z. Lachkar (zouhair.lachkar@env.ethz.ch) ional transport of heat and $\mathrm{CO}_{2}$. Generally though, outside the tropics and Southern Ocean, there are only small variations in meridional transport due to seasonal variations in tracer fields and time variations in eddy transport. For the North Atlantic, eddy variability accounts for up to $10 \%$ and $15 \%$ of the total transport of heat and $\mathrm{CO}_{2}$. This component is not accounted for in coarse-resolution hydrographic surveys.

\section{Introduction}

The ocean absorbs and stores large amounts of heat and anthropogenic $\mathrm{CO}_{2}$, thus playing a key role in mediating climate change. Air-sea fluxes of anthropogenic $\mathrm{CO}_{2}$ cannot be measured directly, but regional variations in these fluxes can be inferred from interior ocean measurements by estimating both meridional transport and storage in the ocean (Wallace, 2001). Precise data-based estimates of meridional carbon transport would be useful to help evaluate simulated anthropogenic $\mathrm{CO}_{2}$ uptake from ocean general circulation models (GCMs). The data-based approach to assess meridional transport of heat and freshwater was first used in the North Atlantic (Wunsch, 1978; Bryden and Hall, 1980; Hall and Bryden, 1982; Roemmich and Wunsch, 1985). Approaches used include the direct method (Hall and Bryden, 1982) and the inversion of hydrographic data (Roemmich and Wunsch, 1985; Macdonald and Wunsch, 1996). Similar inversion methods along with hydrographic measurements of ocean chemical properties were later used to estimate transport of carbon (Brewer et al., 1989; Martel and Wunsch, 1993; Holfort et al., 1998; Ganachaud and Wunsch, 2000) and nutrients

Published by Copernicus Publications on behalf of the European Geosciences Union. 
(Rintoul and Wunsch, 1991; Ganachaud and Wunsch, 2002; Lavin et al., 2003). Because of the potential value of databased estimates of transport across trans-oceanic sections for improving understanding of the global carbon cycle, this effort became one of the main objectives of the World Ocean Circulation Experiment (WOCE).

Nevertheless, there are many uncertainties in these approaches, some of which are related to the temporal variability in the meridional transport of these properties. So far, the observations have been made exclusively during summer months, and only the variability of Ekman transport has been taken into account when calculating annual-mean transports (Álvarez et al., 2003). Yet both ocean circulation and tracer concentration fields vary seasonally in the upper ocean, and they are also affected by the mesoscale activity. Thus, these calculations ignore, or average out, a large part of seasonal variability of velocity and tracer fields that could alter timemean transports estimates. For example, Jayne and Marotzke (2001) found that non-Ekman fluctuations induce an uncertainty in heat transport estimates made from hydrography which may be as large as $0.2 \mathrm{PW}\left(\mathrm{P}=10^{15}\right)$ and $0.4 \mathrm{PW}$ in the midlatitudes of the Atlantic and the Pacific Oceans, respectively. Hall and Bryden (1982) assessed the potential error introduced by eddy noise on their estimate of the heat transport at $24^{\circ} \mathrm{N}$ and found that it might be as large as $25 \%$ of the total. Therefore, to provide reliable estimates of anthropogenic $\mathrm{CO}_{2}$ uptake from transport estimates, we must first be able to properly assess temporal variations in transport. Whereas the seasonal- and eddy-driven variations in heat transport have received much attention (Bryden, 1979; Bryden and Heath, 1985; Bryden and Brady, 1989; Wilkin et al., 1995; Lee and Marotzke, 1997, 1998; Stammer, 1998; Wunsch, 1999; Böning et al., 2001; Jayne and Marotzke, 2001; Volkov et al., 2008), less work has been devoted to investigate seasonal and mesoscale variability of the meridional transport of anthropogenic $\mathrm{CO}_{2}$. The time dependence of anthropogenic $\mathrm{CO}_{2}$ transport thus represents a gap in our understanding of the ocean uptake of $\mathrm{CO}_{2}$.

Here, our objective is to investigate the seasonal and eddy variability of the ocean's meridional transport of anthropogenic $\mathrm{CO}_{2}$. We used an eddy-permitting GCM to study the effects of both the seasonal cycle and mesoscale variability of transport. For comparison, we also examine the meridional transport of heat. We devote a particular attention to the contribution of mesoscale eddy variability to the meridional transport of heat and $\mathrm{CO}_{2}$, as this is neither resolved in time nor in space in most synoptic hydrographic surveys. Finally, we assess to what extent such variability could alter one-time hydrographic estimates of meridional transport of $\mathrm{CO}_{2}$ and heat. In order to gain insight into the mechanisms driving the transport variability, we follow the lead of Lee and Marotzke (1998) and Jayne and Marotzke (2001), who decomposed the ocean circulation into different dynamical components.

\section{Methods}

\subsection{Strategy}

We made global simulations of anthropogenic $\mathrm{CO}_{2}$ using an eddy-permitting version of the ORCA-LIM global ice-ocean model with $\frac{1}{2}^{\circ} \cos \varphi \times \frac{1}{2}^{\circ}$ grid (ORCA05, where $\varphi$ is latitude) and 46 vertical levels. The average horizontal grid size is $34 \mathrm{~km}$. This is actually an intermediate-resolution model that features substantial mesoscale eddy activity particularly in the Southern Ocean and near the western boundary currents, even though its eddy kinetic energy is, on average, about one fourth of that from TOPEX/Poseidon altimetry observations (Lachkar et al., 2007). It is implicitly assumed that the overall qualitative picture would remain similar in future higher resolution simulations, while the quantitative details presented here may change. However, this needs to be confirmed through a series of future finer GCM runs. The main goal of using an eddy-permitting model is to provide a characterization of patterns of the simulated mesoscale variability in the meridional transport of anthropogenic $\mathrm{CO}_{2}$.

Following conventional practice, we computed eddy fluxes from covarying fluctuations in velocity and tracer fields, relying on 5-day average model output. Model results were compared to GLODAP data-based estimates of anthropogenic $\mathrm{CO}_{2}$ (Key et al., 2004). In addition, comparing our simulated heat transport variability with previous observational and model-based estimates helped us to further validate our model results. We also made anthropogenic $\mathrm{CO}_{2}$ simulations with the same model, but at coarse-resolution $\left(2^{\circ} \cos \varphi \times 2^{\circ}\right)$ as typically done in the current generation of climate and carbon models. The comparison between these eddying and non-eddying simulations helped isolate the transport directly associated with resolved mesoscale eddies.

\subsection{Model details}

Our dynamic simulations were made with the ORCA-LIM global ice-ocean model, whose ocean component, the OPA model (Océan PArallélisé, version 9) is coupled to the dynamic-thermodynamic Louvain-la-Neuve sea-ice model (LIM) (Fichefet and Maqueda, 1997). A full description of OPA is provided in Madec and Imbard (1996) and Madec et al. (1998). The model has 46 vertical levels with a vertical grid resolution varying from $6 \mathrm{~m}$ at the surface to $250 \mathrm{~m}$ at the bottom. Vertical mixing coefficients are computed from a second-order closure scheme based on a prognostic equation for turbulent kinetic energy (TKE) (Gaspar et al., 1990; Blanke and Delecluse, 1993). Lateral tracer mixing occurs along isopycnal surfaces (Cox, 1987). Further details of the model physics are given in Lachkar et al. (2007). The bathymetry is calculated using the $2^{\prime}$ bathymetry file ETOPO2 from NGDC (National Geophysical Data Center) (Smith and Sandwell, 1997; Jakobsson et al., 2000), except for the zone south of $72^{\circ} \mathrm{S}$ where it was computed from the 
BEDMAP data (Lythe and Vaughan, 2001). Initial conditions for the temperature and salinity fields were taken from Levitus et al. (1998) for the low and middle latitudes and from the PHC2.1 climatology (Steele et al., 2001) for high latitudes. The model was started from rest, then spun up for 8 years with a climatological seasonal forcing with daily frequency as computed from the 1992-2000 NCEP/NCAR 10-m wind stress and 2-m air temperature data (Kalnay et al., 1996). Additionally, we used monthly climatologies of precipitation (Xie and Arkin, 1996), relative humidity (Trenberth et al., 1989), and total cloud cover (Berliand and Strokina, 1980). Surface heat fluxes and freshwater flux for ocean and sea-ice were calculated using the empirical bulk parameterisations proposed by Goose (1997), which yield more realistic results than does traditional restoring of seasurface temperature and salinity (Large et al., 1997; Gent et al., 1998).

To reduce computational costs, we used the offline model to simulate anthropogenic $\mathrm{CO}_{2}$. The offline model is a tracertransport version of OPA (OPA Tracer 8.5) that was driven by 5-day fields of advection and vertical turbulent diffusion that were computed previously by the dynamic (online) version of the model. Furthermore, we used a perturbation approach to model anthropogenic $\mathrm{CO}_{2}$ in order to further reduce the exhorbitant computational time and memory that would otherwise be needed to make long global carbon simulations at eddy-permitting resolution to near-steady state conditions. Typically, such simulations would need to be integrated for several thousand years. This perturbation approach was introduced by Siegenthaler and Joos (1992) and first used in a 3-D model by Sarmiento et al. (1992). It assumes that the natural ocean carbon cycle is not affected directly by the anthropogenic perturbation, which means we can treat anthropogenic $\mathrm{CO}_{2}$ as a passive transient tracer. For further details about these anthropogenic $\mathrm{CO}_{2}$ simulations, including their boundary conditions, see Lachkar et al. (2007).

\section{Results}

\subsection{Comparison with GLODAP}

Figure 1 shows global and basin zonal integrals of simulated anthropogenic $\mathrm{CO}_{2}$ inventories compared to those for the GLODAP data-based estimates. The simulated anthropogenic $\mathrm{CO}_{2}$ inventories generally match the data-based estimates, altough there are excesses in the tropical and subtropical Pacific Ocean and deficiencies at high latitudes. The high-latitude deficiencies are linked to the weak simulated penetration of anthropogenic $\mathrm{CO}_{2}$ in the upper ocean (see Supplementary Fig. $1 \mathrm{http}: / / w w w . b i o g e o s c i e n c e s . n e t / 6 /$ 2509/2009/bg-6-2509-2009-supplement.pdf). This artefact results from a known deficiency of the ORCA model that stems partly from the model's overly weak vertical mixing in this region due to a shallow mixed layer associated with the formulation of the model's TKE parameterization (Lachkar et al., 2007).

Despite adequate data-model agreement, potential systematic errors in the GLODAP data-based estimates for anthropogenic DIC (Matsumoto and Gruber, 2005; Waugh et al., 2006; Álvarez et al., 2009; Vázquez-Rodríguez et al., 2009) compromise our ability to use that tracer by itself as a reference to validate models (Orr et al., 2001). Anthropogenic DIC is clearly not of the same value as CFC-11, which is measured directly. Previously though, we have evaluated the same model with CFC-11 in Lachkar et al. (2007) and Lachkar et al. (2009).

\subsection{Seasonal variability of meridional transports of $\mathrm{CO}_{2}$ and heat}

\subsubsection{Meridional overturning}

The meridional transport of a tracer depends both on its spatial distribution in the ocean and on the overturning circulation. One metric of the annual cycle of the overturning stream function is simply the difference between mean conditions in July and January (Fig. 2). Unlike the time-mean overturning circulation (see Supplementary Fig. 2 http://www.biogeosciences.net/6/2509/2009/ bg-6-2509-2009-supplement.pdf), the seasonally varying component is symmetric about the equator and largely depth independent, with the return flow for the surface currents showing no deep reversals. These differences between the time-mean and seasonal overturning circulations are consistent with previous studies (Bryan, 1982; England et al., 1994; Böning and Herrmann, 1994; Wacongne and Pacanowski, 1996; Garternicht and Schott, 1997; Lee and Marotzke, 1998; Jayne and Marotzke, 2001). The amplitude of the annual cycle of the overturning circulation in the equatorial region is about 75 Sverdrups $\left(1 \mathrm{~Sv}=10^{6} \mathrm{~m}^{3} \mathrm{~s}^{-1}\right)$ for the World Ocean, with $15 \mathrm{~Sv}$ from the Atlantic Ocean and $60 \mathrm{~Sv}$ from the IndoPacific Ocean. While the fluctuations in the zonal wind stress drive a corresponding change in the northward Ekman mass transport, there is a rapid adjustment to these wind stress anomalies owing to geostrophy and gravity waves that balance the changes in Ekman transport (Willebrand et al., 1980; Jayne and Marotzke, 2001). Thus, there is no net mass transport across a zonal section. Nevertheless, when integrated vertically, there is a net meridional transport for anthropogenic $\mathrm{CO}_{2}$ and heat because anthropogenic $\mathrm{CO}_{2}$ concentrations and temperatures are much higher in the Ekman layer than in the compensating deep return flow.

\subsubsection{Meridional transports of heat and anthropogenic $\mathrm{CO}_{2}$}

Figures 3 and 4 show the meridional transport in terms of its annual-mean and annual cycle for heat and anthropogenic $\mathrm{CO}_{2}$, respectively. Although transported by the 

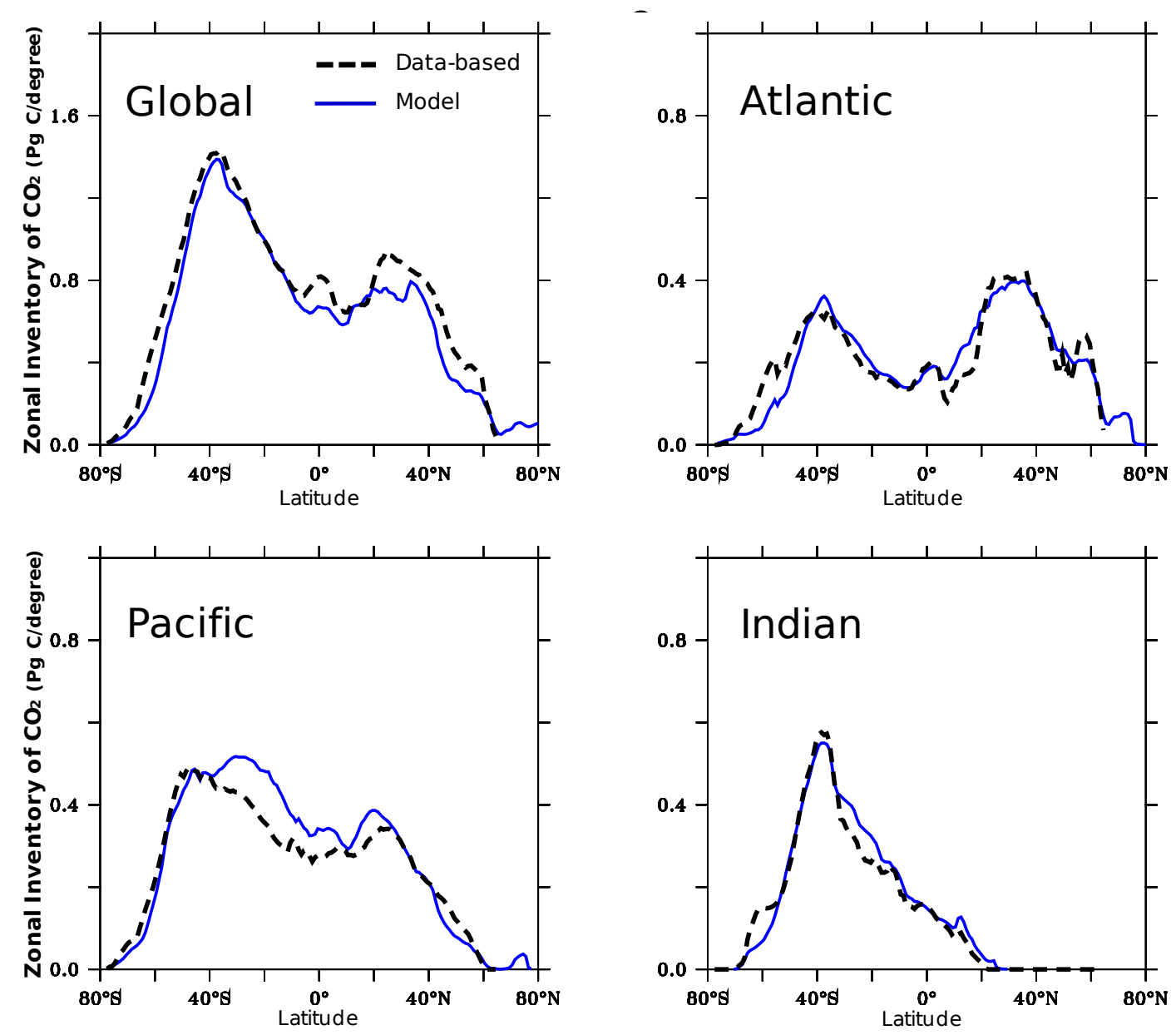

Fig. 1. Zonally global and basin-integrated inventories of anthropogenic $\mathrm{CO}_{2}$ per degree of latitude, from data-based estimate (black dashes, GLODAP) and as simulated by the eddy-permitting model (blue) at end of year 1994.

same circulation, the two tracers have different annualmean transports owing to their contrasting vertical and meridional distributions in the upper ocean (see Supplementary Fig. 3 http://www.biogeosciences.net/6/2509/2009/ bg-6-2509-2009-supplement.pdf). Annual-mean heat transport is asymmetric about the equator with maximum northward transport of $1.5 \mathrm{PW}$ at $15^{\circ} \mathrm{N}$ versus maximum southward transport of about $1 \mathrm{PW}$ at $10^{\circ} \mathrm{S}$. Conversely, annualmean meridional transport of anthropogenic $\mathrm{CO}_{2}$ in 1994 is northward everywhere with two maxima of $0.3{\mathrm{PgC} \mathrm{yr}^{-1}}^{-1}$ and $0.2{\mathrm{PgC} \mathrm{yr}^{-1}}^{-1} 45^{\circ} \mathrm{S}$ and $15^{\circ} \mathrm{N}$, respectively.

Seasonal variability of meridional transport is much more similar for the two tracers because both are driven by seasonal circulation differences that are largely depthindepedant, symmetric about the equator, and dominated by the tropical dynamics. For example, both tracers exhibit their largest seasonal variability within $20^{\circ}$ of the equator, and both have similar patterns across the equator. Within $20^{\circ}$ of the equator, the annual cycle of transport (July minus January) is negative, and its magnitude is maximum around $10^{\circ}$ in each hemisphere. The annual cycle for the global heat transport has a peak-to-peak amplitude that varies between 6 and $8 \mathrm{PW}$ near the equator and ranges from 1.5 to $2 \mathrm{PW}$ in the subtropics.

The structure for the annual cycle of heat in our simulation is remarkably similar to that obtained by Jayne and Marotzke (2001) using a $\frac{1}{4}^{\circ}$ eddy-permitting model, although the peak-to-peak amplitude found in their model is $25 \%$ smaller, ranging between 4.5 and $6 \mathrm{PW}$ in the equatorial region and between 1 and $1.5 \mathrm{PW}$ in the subtropics. Such differences may arise in part because our model is forced with wind stress and temperature from NCEP climatology, whereas Jayne and Marotzke (2001) used the ECMWF reanalyses. Our simulated annual cycle for heat in the equatorial region also agrees well with the estimate of Carissimo et al. (1985), who used satellite-derived net radiation balances and atmospheric transports and found that seasonal amplitude of heat transport was between 7 and 8 PW. Relative to heat transport, the annual cycle of anthropogenic $\mathrm{CO}_{2}$ transport has a similar structure with an amplitude varying 
between $1.2 \mathrm{PgC}^{-1}$ and $1.5 \mathrm{Pg} \mathrm{Cyr}^{-1}$ in the equatorial region and between $0.3 \mathrm{Pg} \mathrm{Cyr}^{-1}$ and $0.4 \mathrm{PgC} \mathrm{yr}^{-1}$ at subtropical latitudes.

Unlike for the annual-mean transport, the Atlantic basin contributes the least to the seasonally varying transport with a peak-to-peak amplitude at $8^{\circ} \mathrm{N}$ that is less than $2 \mathrm{PW}$ for heat and less than $0.3 \mathrm{PgC} \mathrm{yr}^{-1}$ for anthropogenic $\mathrm{CO}_{2}$. This weak transport results from the relatively weak seasonal overturning circulation in this basin relative to the IndoPacific Ocean (Fig. 2). For a better mechanistic understanding of the processes driving the annual cycle of meridional transport, we decomposed the meridional velocity into various dynamical components.

\subsubsection{Mechanisms: dynamical decomposition}

Following Lee and Marotzke (1998), the meridional velocity component was broken down into three separate components:

$$
\begin{aligned}
v(x, y, z)= & {\left[v_{e}(x, y, z)-\frac{1}{h} \int_{-h}^{0} v_{e}(x, y, z) d z\right] } \\
& +\frac{1}{h} \int_{-h}^{0} v(x, y, z) d z+v_{\text {baroc }}(x, y, z)
\end{aligned}
$$

where $h$ is ocean depth. The first component on the right hande side of Eq. (1) is the Ekman flow minus its barotropic compensation. The Ekman component of velocity, $v_{e}$, is taken to be the shear velocity in the upper $100 \mathrm{~m}$ of ocean referenced to velocity at $100 \mathrm{~m}$ (the tenth level in our model). Most of the Ekman transport takes place in the uppermost $30 \mathrm{~m}$ (top three levels in the model). The second component is the contribution of the non-Ekman meridional velocity associated with the external mode (or barotropic gyre circulation) flowing over varying topography. The third component, $v_{\text {baroc }}$, is the baroclinic velocity which is generally associated with thermal wind shear balanced by zonal density gradients along with smaller contributions from the ageostrophic processes. We refer to these three terms as the Ekman, barotropic, and baroclinic components.

We evaluated how each of these three components contributes to the annual cycle of meridional transport of heat and anthropogenic $\mathrm{CO}_{2}$ (Fig. 5). The seasonally varying Ekman transport is symmetric across the equator because both the Coriolis parameter and the zonal wind seasonal cycle are antisymmetric about the equator. The maximum Ekman variability occurs at $7^{\circ} \mathrm{S}$ and $5^{\circ} \mathrm{N}$ where the seasonal variations in zonal wind are the largest. The Ekman transport is the dominant mechanism driving seasonal variability in the tropics. Very near the equator, there is an increase in the baroclinic southward transport, which compensates a sharp reduction in Ekman transport. However, this dynamic decomposition is meaningless very near the equator where the Ekman transport becomes ill-defined as the Coriolis parameter approaches zero. The increase in the baroclinic transport at the equator expresses the existence of a seasonally varying flow across the equator driven by the water pressure gradient (Schopf, 1980; Philander and Delecluse, 1983; Jayne and
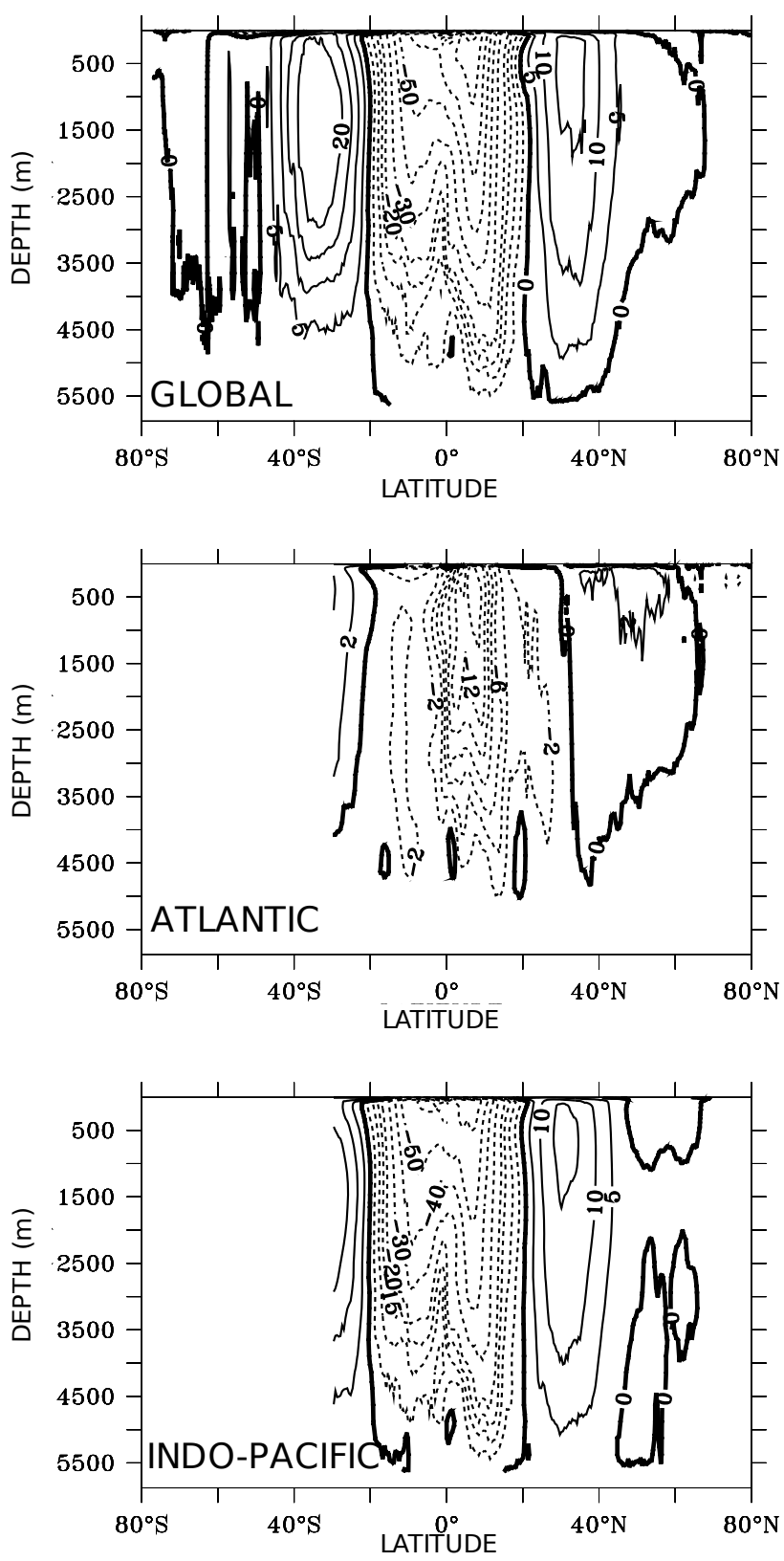

Fig. 2. Simulated seasonal July minus January overturning for the global ocean (top), the Atlantic Ocean (middle), and the IndoPacific Ocean (bottom). Negative values (dotted lines) indicate counterclockwise overturning.

Marotzke, 2001). In the southern extratropics, the baroclinic transport contributes substantially to the seasonal variability. Finally, throughout the ocean there is little contribution to the seasonal variability of meridional transport from the barotropic gyre circulation. The dominance of the Ekman transport component explains why the annual cycle of meridional transport is similar for both tracers.

Having studied the seasonally varying transport of heat and anthropogenic $\mathrm{CO}_{2}$, we now turn our attention to the 

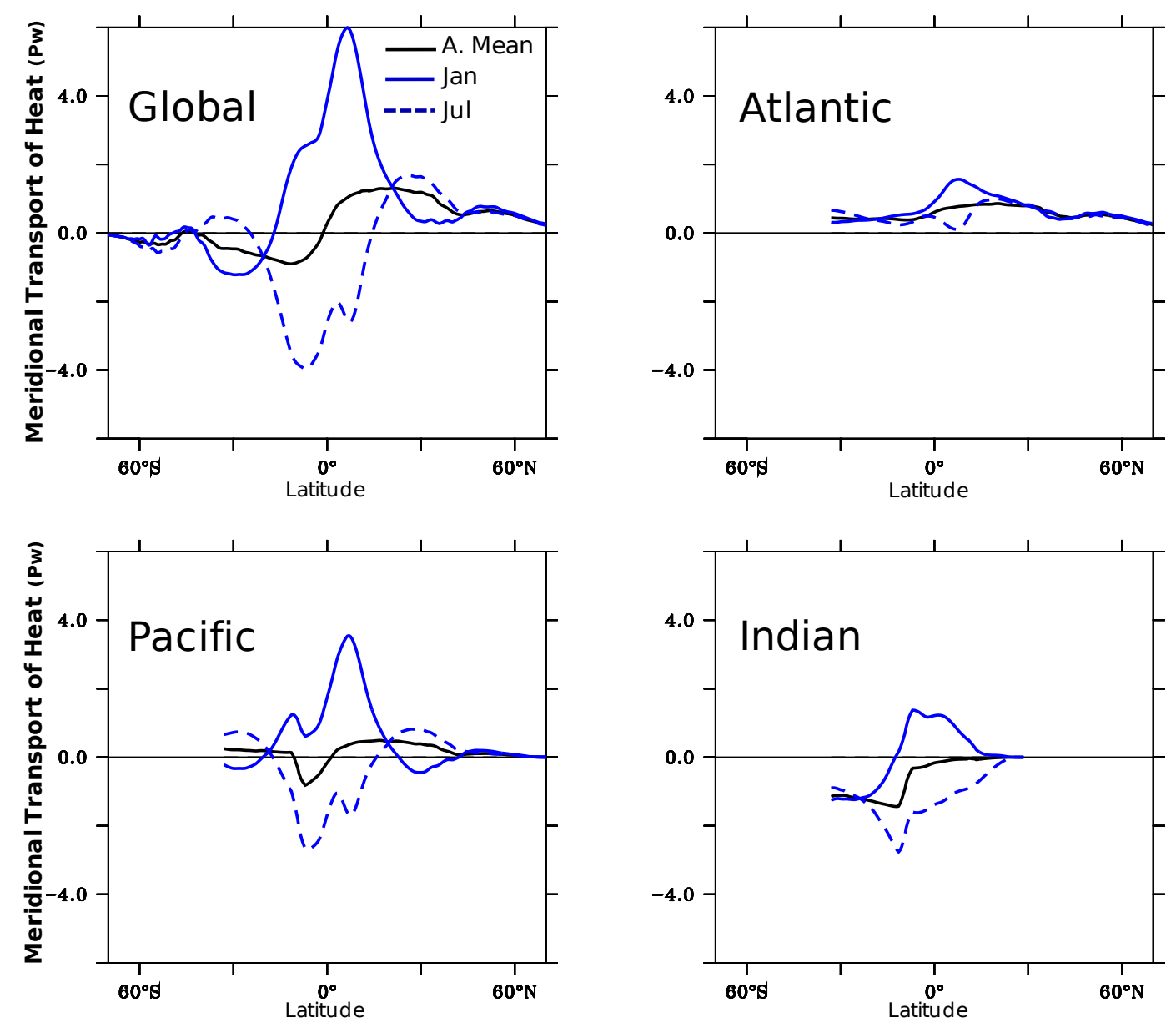

Fig. 3. Global- and basin-integrated meridional transport of heat for January (solid blue), July (dashed blue), and the annual-mean (solid black).

contribution of the mesoscale variability to the time-mean transport of both tracers.

\subsection{Eddy transport of $\mathrm{CO}_{2}$ and heat}

\subsubsection{Characteristics of eddy transport}

Here we explore the characteristics of the eddy transport of $\mathrm{CO}_{2}$ and heat in an eddy-permitting GCM. We examine the spatial distributions of the eddy transport, and investigate its physical nature for both tracers. The eddy transport for a tracer results from the covariance of fluctuations in its concentration and fluctuations in advective velocities, both relative to their time means. This so-called "rectified" eddy transport (hereafter referred to as eddy transport) contributes to the annual-mean transport and is generally associated with mesoscale activity (Thompson, 1993; Jayne and Marotzke, 2002); however, it may also result from other high-frequency variability processes such as tropical instability waves (Qiao and Weisberg, 1998).
In recent decades, there has been considerable debate about the the transport of heat by mesoscale eddies. In contrast, the eddy transport of the transient tracers, e.g., anthropogenic $\mathrm{CO}_{2}$, has not been evaluated. Eddies affect not only the time-varying component of meridional transport but also the time-mean. To place the eddy transport of anthropogenic $\mathrm{CO}_{2}$ in context, we first evaluate our simulated eddy heat transport in terms of previous observational and eddypermitting model estimates.

We computed the time-mean, depth-integrated, meridional eddy heat transport $H_{e}$ from the model output using the identity:

$H_{e}(x, y)=\int_{-h}^{0} \rho c_{p}[\overline{v \theta}-\bar{v} \bar{\theta}] d z$

where $\rho$ is the in-situ density, $c_{p}$ is the heat capacity of seawater, $\theta$ is the potential temperature, $v$ is the meridional velocity, and $h$ is the ocean depth. The overbar represents the annual-mean. Zonally integrated, meridional eddy transport of heat computed from Eq. (2) is shown in Fig. 6a. 

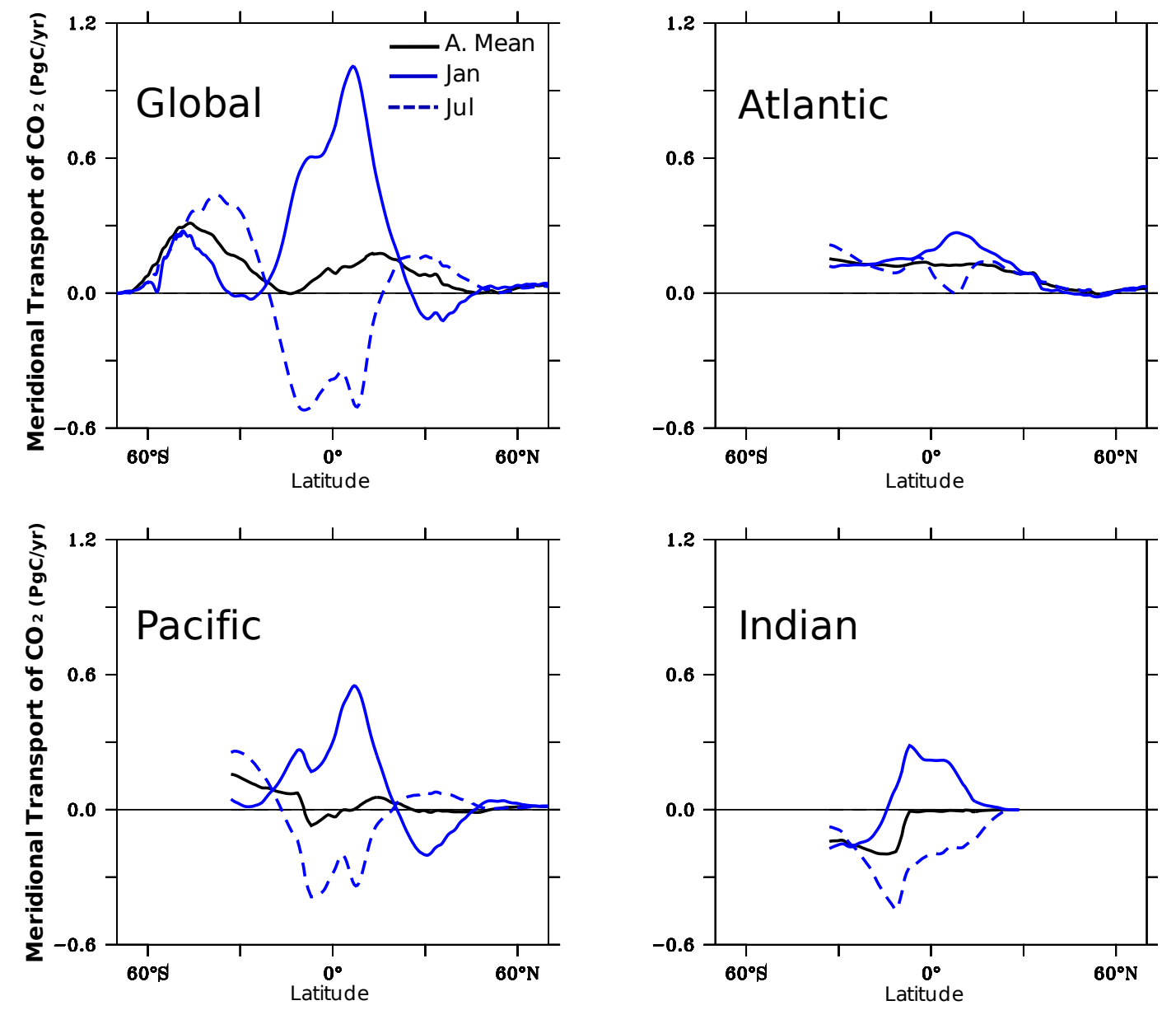

Fig. 4. Global and basin integrated meridional transport of anthropogenic $\mathrm{CO}_{2}$ for January (solid blue), July (dashed blue), and the annualmean (solid black).

There is large poleward eddy heat transport in the Southern Ocean and between the tropics. Maxima in meridional transports are associated with the North Equatorial Counter Current in the Pacific Ocean and the Antarctic Circumpolar Current (ACC) in the Southen Ocean. Our results for eddy heat transport are remarkably similar to those by Jayne and Marotzke (2002), who used a $\frac{1}{4}^{\circ}$ eddy-permitting GCM. Our model simulates $0.2 \mathrm{PW}$ of southward eddy transport between $60^{\circ} \mathrm{S}$ and $40^{\circ} \mathrm{S}$, which is similar to data-based estimates of $0.45 \pm 0.3 \mathrm{PW}$ by de Szoeke and Levine (1981) and $0.3 \mathrm{PW}$ by Stammer (1998). Our estimate is also consistent with the work of Marshall et al. (1993) who predicted $0.25 \mathrm{PW}$ of eddy heat transport from an analytical model of the zonally averaged ACC, but it is larger than the 0.14 PW of eddy heat transport across the ACC as simulated in Fine Resolution Antarctic Model (FRAM) (Thompson, 1993). Conversely, our estimate is lower than the observed time-mean eddy transport obtained by both Bryden (1979) at Drake Passage (0.5 PW) and by Macdonald and Wunsch (1996) at $30^{\circ} \mathrm{S}(0.9 \pm 0.3 \mathrm{PW})$. Between $40^{\circ} \mathrm{S}$ and $45^{\circ} \mathrm{S}$, our estimate of $0.2 \mathrm{PW}$ is lower than the $0.6 \mathrm{PW}$ esti- mate by Jayne and Marotzke (2002), even though the general structure is similar elsewhere. Near the equator, our simulated eddy heat transport agrees well both in structure and magnitude with the estimates of $0.85 \mathrm{PW}$ for the southward transport at $5^{\circ} \mathrm{N}$ and $0.4 \mathrm{PW}$ for the northward transport at $5^{\circ} \mathrm{S}$ by Jayne and Marotzke (2002). Furthermore, this large convergent eddy heat transport at the equator is also consistent with observations (Bryden and Brady, 1989) as well as previous modelling work by Philander and Pacanowski (1986). Farther from the equator there is a second important peak in eddy heat transport in the Indian Ocean between $10^{\circ} \mathrm{S}$ and $15^{\circ} \mathrm{S}$. There is also a northward eddy transport maximum of about $0.1 \mathrm{PW}$ in the North Atlantic $\left(45^{\circ} \mathrm{N}\right)$, related to the Gulf Stream mesoscale variability in agreement with Jayne and Marotzke (2002). In the North Pacific, there is a northward eddy heat transport of about $0.05 \mathrm{PW}$ in the latitudinal band $30^{\circ}-40^{\circ} \mathrm{N}$ associated with the Kuroshio Current. This is slightly lower than the recent observationbased estimate of Qiu and Chen (2004) who found about $0.1 \mathrm{PW}$ eddy poleward transport in the Pacific basin at these latitudes. In summary, our model exhibits similar overall 

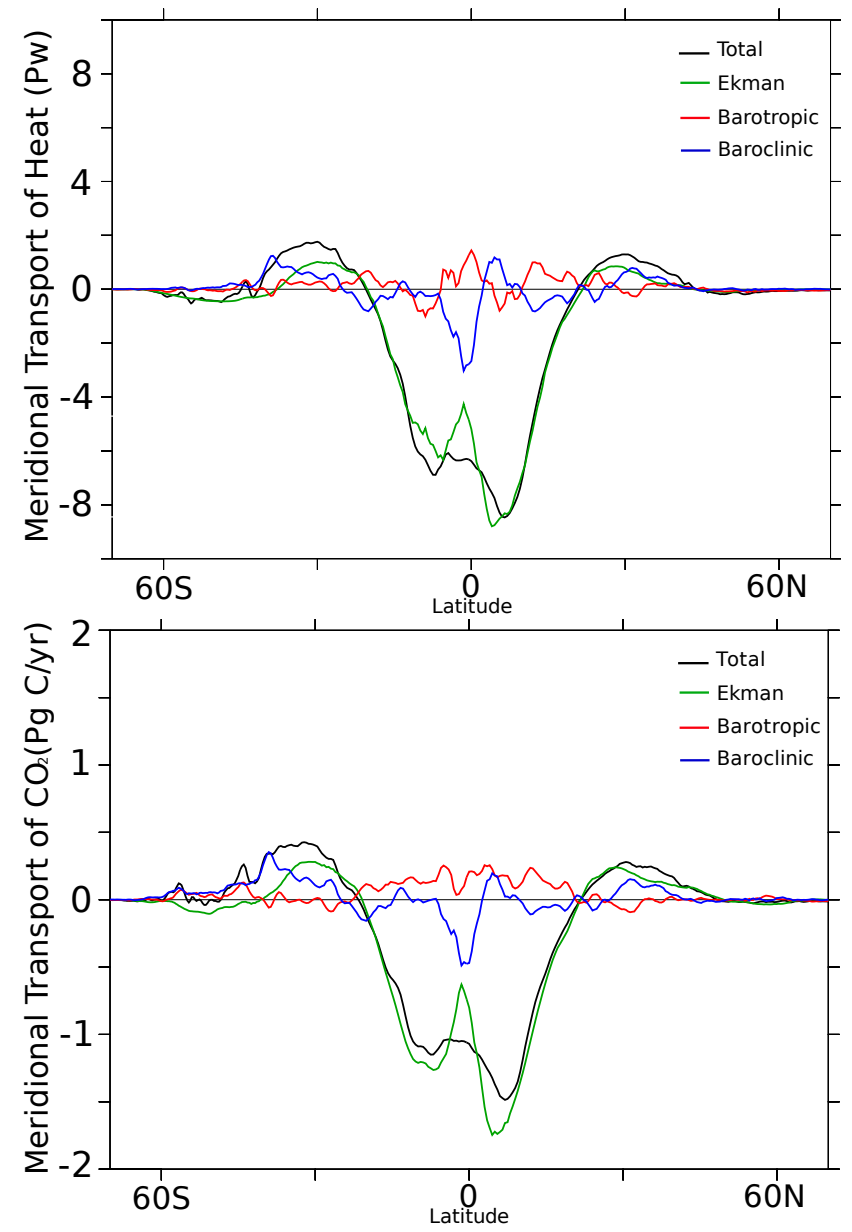

Fig. 5. Decomposition of the annual cycle of total meridional transport (black), defined as the July minus January difference, into barcolinic (blue), barotropic (red), and Ekman (green) components for heat (top) and anthropogenic $\mathrm{CO}_{2}$ (bottom).

structure of annual-mean, meridional eddy heat transport as found in previous observational and modelling studies; however, it probably underestimates the magnitude of transport, particularly at mid southern and northern latitudes, because its eddy-permitting horizontal grid only resolves part of the eddy spectrum.

As for heat transport, we also computed the depthintegrated, annual-mean, eddy transport of anthropogenic $\mathrm{CO}_{2}, T_{e}$ using a similar equation:

$T_{e}(x, y)=\int_{-h}^{0}[\overline{v c}-\bar{v} \bar{c}] d z$

where $c$ is the concentration of anthropogenic $\mathrm{CO}_{2}, v$ is the meridional velocity, and $h$ is the depth of the ocean.

Figure $6 \mathrm{~b}$ shows global and basin zonal integrals of the eddy transport of anthropogenic $\mathrm{CO}_{2}$. The overall structure of the eddy transport of anthropogenic $\mathrm{CO}_{2}$ resembles that for heat (Fig. 6a). Discrepancies exist, however, including
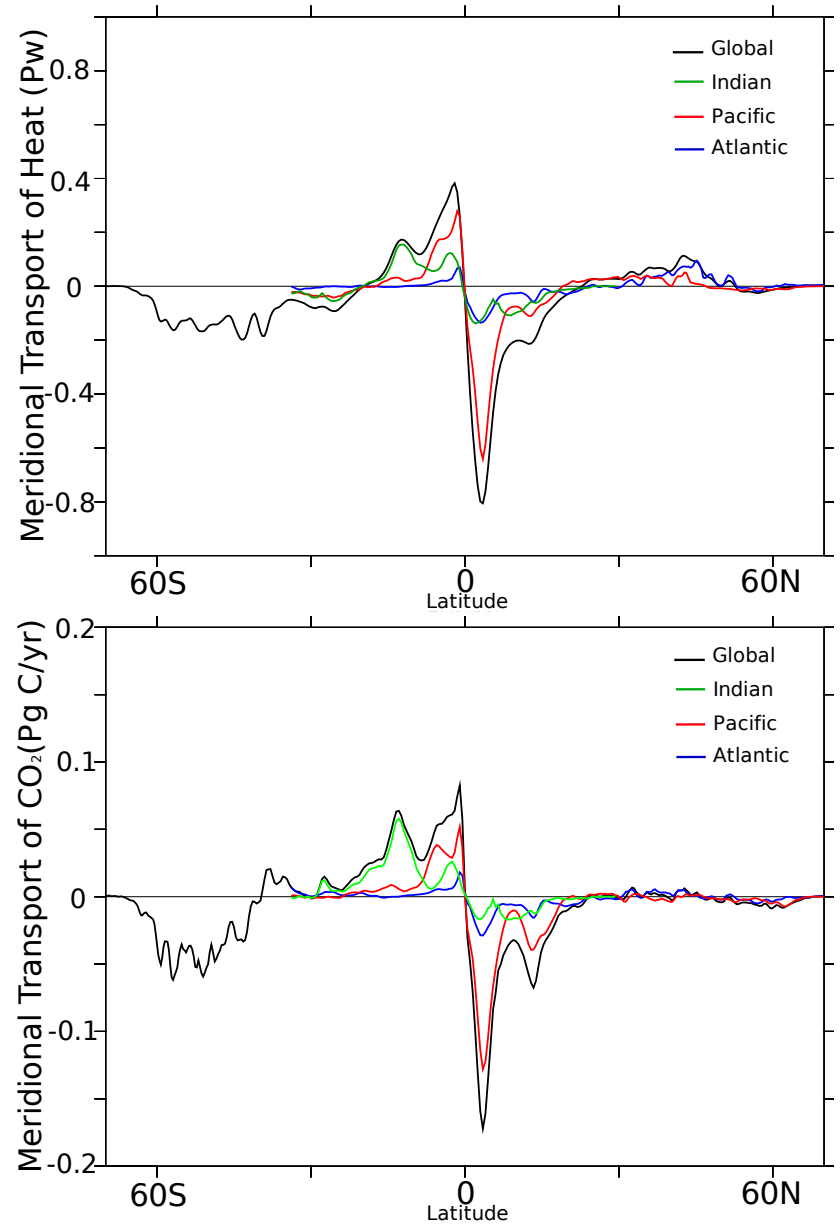

Fig. 6. Zonally integrated meridional eddy transport of heat (top) and anthropogenic $\mathrm{CO}_{2}$ (bottom) over the global ocean (black) and in the Atlantic (blue), Pacific (red) and Indian (green) basins.

the larger peak of northward transport for anthropogenic $\mathrm{CO}_{2}$ in the Indian basin between $10^{\circ} \mathrm{S}$ and $15^{\circ} \mathrm{S}$, which is comparable to the maximum in global northward transport at the equator. Also, there is a relatively larger maximum of southward eddy transport of anthropogenic $\mathrm{CO}_{2}$ at $15^{\circ} \mathrm{N}$ in the North Pacific. In the southern mid latitudes, southward eddy transport of $\mathrm{CO}_{2}$ is relatively larger than for heat between $60^{\circ} \mathrm{S}$ and $50^{\circ} \mathrm{S}$, reaching $0.05 \mathrm{Pg} \mathrm{C} \mathrm{yr}^{-1}$ which represents up to $20 \%$ of the total annual-mean transport of $\mathrm{CO}_{2}$ at these latitudes. In contrast, eddies associated with the Gulf Stream and the Kuroshio Current contribute very little to the meridional transport of $\mathrm{CO}_{2}$.

\subsubsection{Dynamics of the eddy transport}

Our computation of the rectified eddy transport includes not only variability due to the mesoscale activity but also variability associated with other features such as propagation of large-scale waves and Ekman layer fluctuations. Thompson (1993) simulated the meridional heat transport across the 

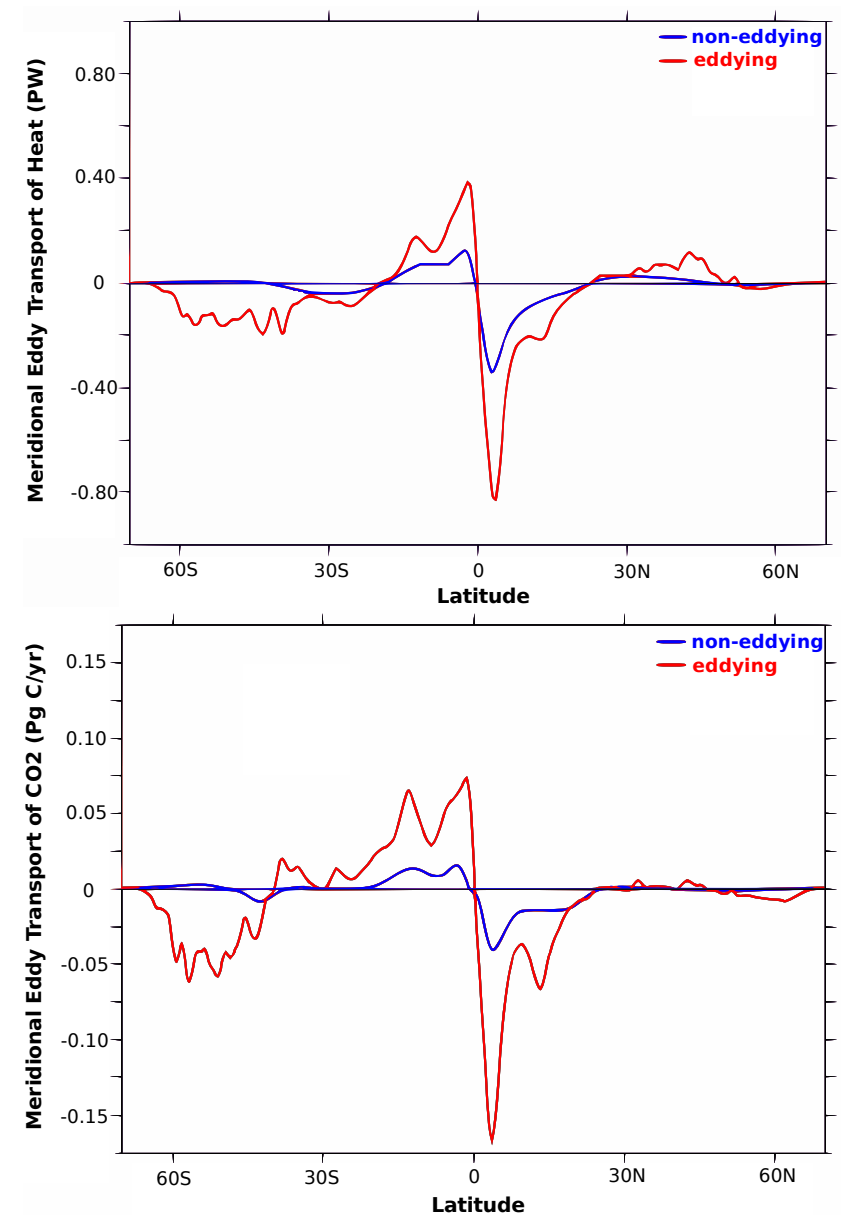

Fig. 7. Zonally and vertically integrated meridional eddy transport of heat (top) and anthropogenic $\mathrm{CO}_{2}$ (bottom) as simulated using the coarse-resolution (blue) and the eddy-permitting (red) versions of the model.

ACC using the FRAM model, showing that mesoscale activity largely dominates the large-scale contribution to the rectified eddy transport. Here, to discriminate between these processes and to evaluate the contribution of the resolved mesoscale eddies to the rectified eddy transport, we compared our eddy-permitting simulations to analagous simulations made with a coarse-resolution version of the same model (Fig. 7). In the coarse-resolution model, annual-mean eddy transport of both heat and anthropogenic $\mathrm{CO}_{2}$ is negligible at mid and high latitudes, particularly in the Southern Hemisphere. Thus most of the eddy transport in these regions results from the mesoscale eddy activity, which can only be resolved with the fine-grid model. In contrast near the equator, there is non-negligible, annual-mean eddy transport of heat and anthropogenic $\mathrm{CO}_{2}$ in the coarse-resolution version, although that is substantially smaller than in the eddy-permitting model. Thus in the equatorial region, other processes (e.g., tropical waves and Ekman layer variability) also may contribute to the so-called eddy transport.
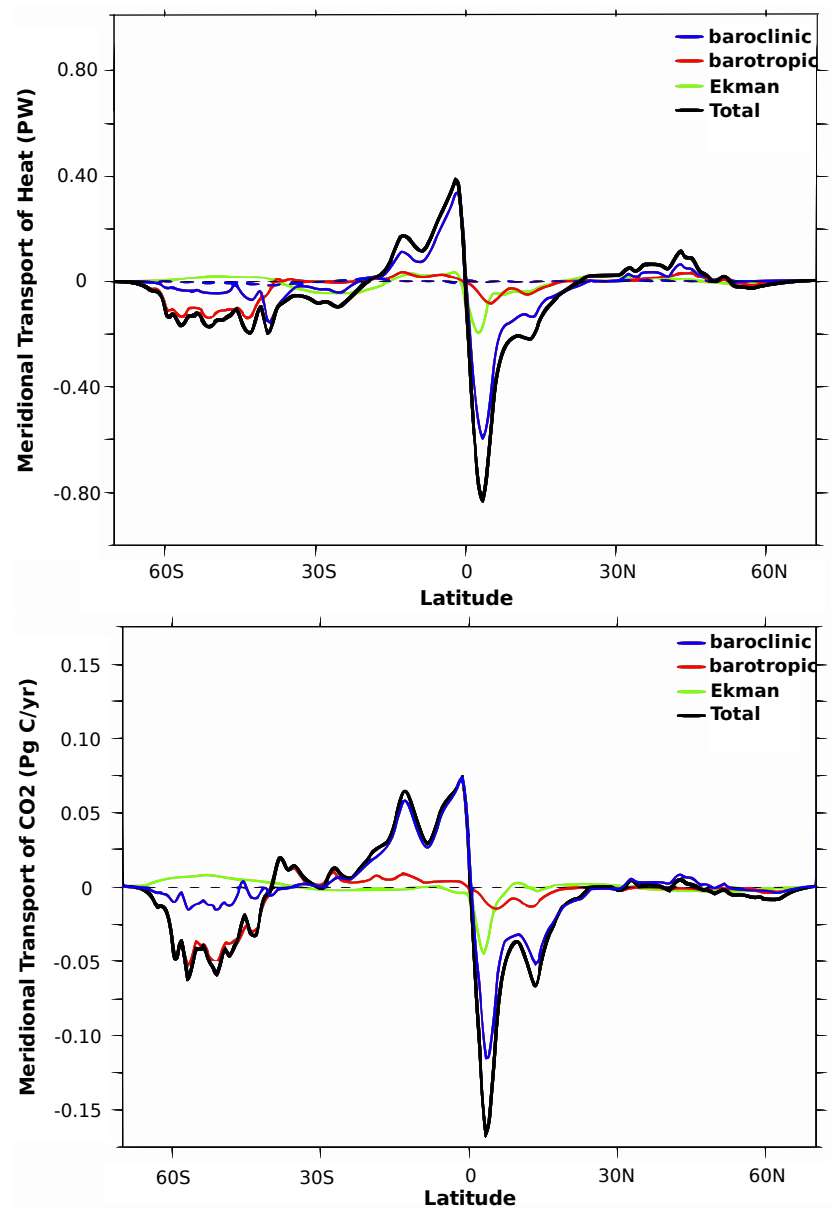

Fig. 8. Decomposition of the total eddy transports (black) of heat (top) and anthropogenic $\mathrm{CO}_{2}$ (bottom) into barcolinic (blue), barotropic (red) and Ekman (green) components.

For an improved understanding of the nature of the meridional eddy transports of heat and anthropogenic $\mathrm{CO}_{2}$, we separated out their dynamical components given in Eq. (1). Figure 8 shows the contributions of these different components to the total eddy transport. The small tropical eddy transport of heat $(0.2 \mathrm{PW})$ and anthropogenic $\mathrm{CO}_{2}\left(0.035 \mathrm{Pg} \mathrm{C}^{-1}\right)$ at $5^{\circ} \mathrm{N}$ that is associated with the Ekman component is due to covarying fluctuations of Ekman velocity and tracer fields. In the extratropics, the Ekman contribution to the eddy transport of heat and anthropogenic $\mathrm{CO}_{2}$, is close to zero. For both heat and anthropogenic $\mathrm{CO}_{2}$, the baroclinic component dominates eveywhere except between $40^{\circ} \mathrm{S}$ and $60^{\circ} \mathrm{S}$ where the barotropic component outweighs the baroclinic contribution. The importance of barotropic eddies at these latitudes illustrates the fundamental role of the bottom topography and the meandering of the ACC in driving southward eddy transport of heat and tracers. These results contrast with those of Jayne and Marotzke (2001) who found that the baroclinic contribution dominates the barotropic component even at southern mid latitudes. One possible cause for this discrepancy 

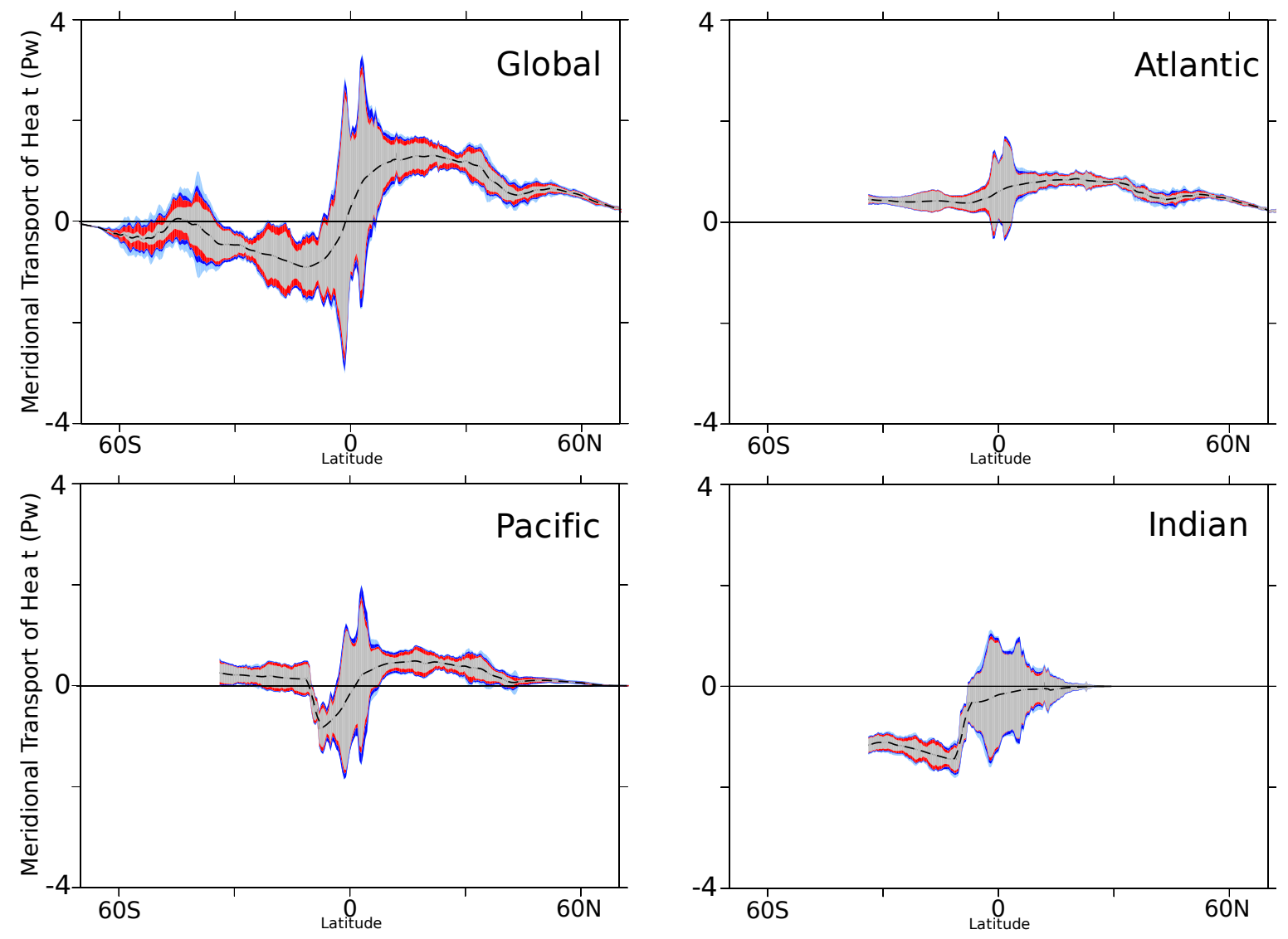

Fig. 9. Root-mean-square variability of heat transport around annual-mean transport (dashed black line) due to the temporal fluctuations in non-Ekman transport (grey shading), temperature seasonality (red shading), and eddy variability as simulated by the high-resolution model ( $34 \mathrm{~km}$, dark blue shading) and low-resolution model (136 km, light blue shading).

may be that the horizontal resolution of our model is not as fine as theirs $\left(0.5^{\circ}\right.$ vs. $\left.0.25^{\circ}\right)$, which could limit development of baroclinic eddies. On the other hand, our finding corroborates results from Cessi and Fantini (2004) who found that the eddy fluxes of heat across zonal periodic current are mainly due to the barotropic component of the eddies. Our finding is also consistent with recent results from Ishida et al. (2007) who found that the eddy transport, while largely dominated by transient baroclinic eddies in the tropical oceans, is mostly due to barotropic standing eddies in the Southern Ocean.

Results from our analysis indicate that there is a strong temporal variability in transport and that eddies contribute substantially to the time-mean transport. Thus one may question whether a synoptic one-time survey of the ocean is representative of the time-mean circulation. In the next section, we investigate the extent to which carbon transport estimates from a hydrographic survey may misrepresent true mean transport due to uncertainties associated with temporal variability and coarse-sampling, where eddy effects are not resolved.

\section{Discussion}

Most measurements that are used for hydrography-based computations of time-mean transport are taken from synoptic surveys, often sampled during summer months. Thus they ignore the impact of the temporal variability on transport. If temporal variability of heat and anthropogenic $\mathrm{CO}_{2}$ transports were large, then estimates from synoptic surveys would be heavily biased. To help quantify this potential bias, we decomposed fluctuations of meridional transport, $T^{\prime}(t)$, of each of the tracers into the three familiar components:

$$
T^{\prime}(t)=v^{\prime}(t) \cdot \bar{c}+\bar{v} \cdot c^{\prime}(t)+\left[v^{\prime}(t) \cdot c^{\prime}(t)-\overline{v^{\prime} c^{\prime}}\right]
$$

where $v$ is the meridional velocity and $c$ is the tracer concentration (for heat $c$ is actually $\rho c_{p} \theta$ ). The overbar represents the annual mean of the quantity and the prime represents the temporal deviation from that mean. $T^{\prime}(t)$ is the deviation of the instantenous transport measured from hydrographic surveys from its annual mean value. The first term on the right-hand side of Eq. (4) is the transport fluctuation due to the variations in velocity acting on the time-averaged tracer 

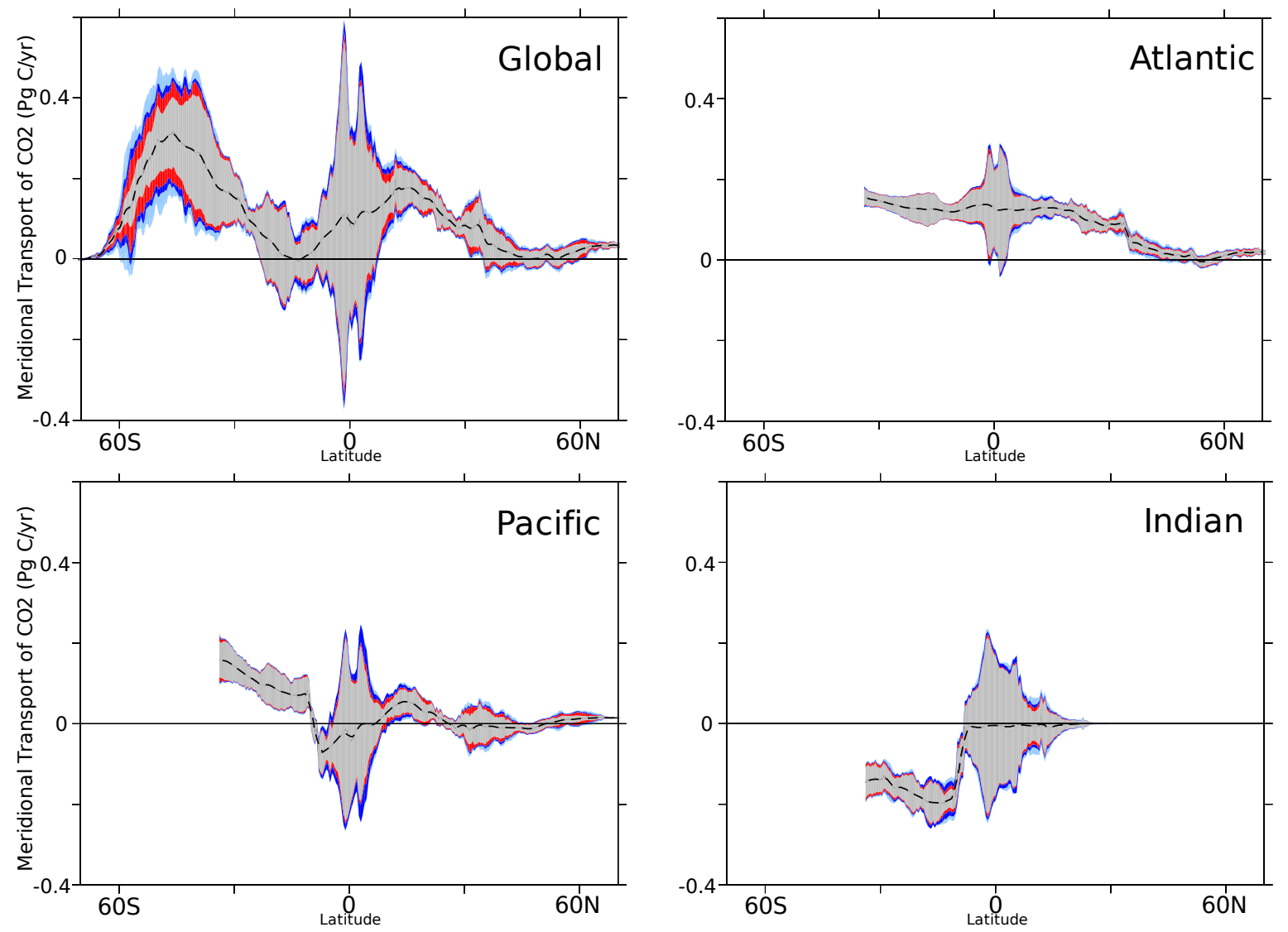

Fig. 10. Root-mean-square variability of anthropogenic $\mathrm{CO}_{2}$ transport around annual-mean transport (dashed black line) due to the temporal fluctuations in non-Ekman transport (grey shading), temperature seasonality (red shading), and eddy variability as simulated by the highresolution model (34 km, dark blue shading) and low-resolution model (136 km, light blue shading).

field. The second term represents how the time-mean velocity field advects variations in the tracer field. The third term represents fluctuations of the eddy transport about its (rectified) annual mean.

The first component may introduce a bias in one-time hydrographic estimates of the annual-mean transport if the variability in the circulation is not taken into account. In general though, the variability associated with the Ekman transport is considered in these studies (Álvarez et al., 2003). Thus, we investigated if fluctuations in non-Ekman transport (barotropic and baroclinic components), which are neglected in such calculations, could substantially alter synoptic survey estimates of time-mean tracer transport. For this analysis, we begin by computing the root-mean-square (RMS) of the transport variability that is associated with the non-Ekman part of the first term on the right-hand side of Eq. (4). Figures 9 and 10 show biases associated with this term for transport estimates of heat and anthropogenic $\mathrm{CO}_{2}$, respectively. In the southern mid latitudes, there is a relatively large variability associated with this term, with a maximum of $0.5 \mathrm{PW}$ for heat transport and about $0.15 \mathrm{Pg} \mathrm{C} \mathrm{yr}^{-1}$ for anthropogenic $\mathrm{CO}_{2}$, which is $50 \%$ of the total transport at these latitudes. Near the equator, variability associated with the non-Ekman transport is generally the largest and it is even larger than the annual-mean transport in each of the three basins, ranging from $1.5 \mathrm{PW}$ to $2.5 \mathrm{PW}$ for heat and from $0.2 \mathrm{Pg} \mathrm{C} \mathrm{yr}^{-1}$ to $0.45 \mathrm{Pg} \mathrm{C} \mathrm{yr}^{-1}$ for anthropogenic $\mathrm{CO}_{2}$. In the extratropical Atlantic, transport variability associated with this term is smaller. For heat transport, it ranges from $0.05 \mathrm{PW}$ in the northern subtropics to $0.12 \mathrm{PW}$ in South Atlantic at $25^{\circ} \mathrm{S}$. For anthropogenic $\mathrm{CO}_{2}$, this bias varies between $0.02 \mathrm{Pg} \mathrm{C} \mathrm{yr}^{-1}$ in the northern subtropics and $0.03 \mathrm{Pg} \mathrm{C} \mathrm{yr}^{-1}$ at $25^{\circ} \mathrm{S}$. In the South Atlantic, this uncertainty can be as large as $35 \%$ of the total heat transport and $20 \%$ of total tranport of anthropogenic $\mathrm{CO}_{2}$. In the North Atlantic, it represents up to $20 \%$ and $30 \%$ of total heat and anthropogenic $\mathrm{CO}_{2}$ transports, respectively.

In the Pacific basin, variability associated with the nonEkman transport is generally larger than in the Atlantic Ocean. Maximum variability in the North Pacific is at $35^{\circ} \mathrm{N}$ where heat transport variabilty is $0.23 \mathrm{PW}(65 \%$ of the annual-mean value) and anthropogenic $\mathrm{CO}_{2}$ variability 
Table 1. Biases in synoptic survey estimates of meridional heat transport (PW) associated with its temporal variability. The data shown are the root-mean-square variability of the three components in Eq. (4) for different locations. Maximum associated uncertainties (ratio of bias to annual-mean transport) are in brackets. Data in the 4th row corresponds to the eddy variability bias estimated using a coarse resolution sampling of $136 \mathrm{~km}$.

\begin{tabular}{lrrrrrr}
\hline & S. Ocean $\left(60^{\circ} \mathrm{S}-40^{\circ} \mathrm{S}\right)$ & \multicolumn{2}{c}{ S. Subtropics $\left(35^{\circ} \mathrm{S}-25^{\circ} \mathrm{S}\right)$} & \multicolumn{2}{c}{ N. Subtropics $\left(25^{\circ} \mathrm{N}-35^{\circ} \mathrm{N}\right)$} \\
& World Ocean & Atlantic & Indian & Pacific & Atlantic & Pacific \\
\hline Non-Ekman & $0.05-0.5(>100 \%)$ & $0.1-0.12(35 \%)$ & $0.12-0.2(20 \%)$ & $0.15-0.25(85 \%)$ & $0.05-0.1(20 \%)$ & $0.1-0.23(65 \%)$ \\
Tracer seasonality & $0.1-0.25(>100 \%)$ & $<0.02(5 \%)$ & $<0.05(8 \%)$ & $<0.12(30 \%)$ & $0.02-0.05(8 \%)$ & $0.04-0.1(40 \%)$ \\
Eddy (High Res.) & $<0.1(>100 \%)$ & $<0.02(5 \%)$ & $<0.02(2 \%)$ & $<0.02(10 \%)$ & $<0.01(3 \%)$ & $0.02(10 \%)$ \\
Eddy (Low Res.) & $0.1-0.45(>100 \%)$ & $<0.03(5 \%)$ & $0.02-0.06(8 \%)$ & $0.03-0.08(40 \%)$ & $0.02-0.1(10 \%)$ & $0.03-0.11(35 \%)$ \\
\hline
\end{tabular}

Table 2. Biases in synoptic survey estimates of meridional anthropogenic $\mathrm{CO}_{2}$ transport $\left(\mathrm{in} \mathrm{Pg} \mathrm{Cyr}^{-1}\right.$ ) associated with its temporal variability (same as in Table 1).

\begin{tabular}{lrrrrrr}
\hline & S. Ocean $\left(60^{\circ} \mathrm{S}-40^{\circ} \mathrm{S}\right)$ & \multicolumn{2}{c}{ S. Subtropics $\left(35^{\circ} \mathrm{S}-25^{\circ} \mathrm{S}\right)$} & \multicolumn{3}{c}{ N. Subtropics $\left(25^{\circ} \mathrm{N}-35^{\circ} \mathrm{N}\right)$} \\
& World Ocean & Atlantic & Indian & Pacific & Atlantic & Pacific \\
\hline Non-Ekman & $0.02-0.15(50 \%)$ & $0.02-0.03(20 \%)$ & $0.03-0.05(30 \%)$ & $0.03-0.06(40 \%)$ & $0.01-0.02(30 \%)$ & $0.02-0.05(>100 \%)$ \\
Tracer seasonality & $0.01-0.06(40 \%)$ & $<0.01(2 \%)$ & $<0.01(5 \%)$ & $<0.01(4 \%)$ & $<0.01(10 \%)$ & $0.01-0.02(>100 \%)$ \\
Eddy (High Res.) & $0.01-0.03(20 \%)$ & $<0.01(2 \%)$ & $<0.01(4 \%)$ & $<0.01(2 \%)$ & $<0.01(5 \%)$ & $<0.01(>100 \%)$ \\
Eddy (Low Res.) & $0.02-0.1(70 \%)$ & $<0.01(2 \%)$ & $<0.015(10 \%)$ & $<0.01(5 \%)$ & $<0.015(15 \%)$ & $<0.02(>100 \%)$ \\
\hline
\end{tabular}

reaches $0.048 \mathrm{Pg} \mathrm{Cyr}^{-1}$, well above the annual mean transport that is close to zero. In the South Pacific, at $35^{\circ} \mathrm{S}$, the bias reaches $0.24 \mathrm{PW}$ for heat transport (70\% of the annual mean-transport) and $0.055 \mathrm{Pg} \mathrm{C} y r^{-1}$ for anthropogenic $\mathrm{CO}_{2}$ (35\% of the total transport). This variability is also important in the Indian Ocean, in particular due to intensive monsoon activity between $15^{\circ} \mathrm{S}$ and $30^{\circ} \mathrm{S}$, where it varies between 0.13 and $0.28 \mathrm{PW}$ for heat transport (12\% to $20 \%$ of the annual mean-transport) and between $0.03 \mathrm{Pg} \mathrm{C} \mathrm{yr}^{-1}$ and $0.05 \mathrm{Pg} \mathrm{Cyr}^{-1}$ for anthropogenic $\mathrm{CO}_{2}$ (up to $30 \%$ of the annual mean-transport). More details about uncertainties in hydrography-based transport estimates related to non-Ekman fluctuations are available in Tables 1 and 2.

The second term in Eq. (4), due to the seasonal variability of the tracer concentrations, also contributes to temporal variability and is not accounted for in the hydrographic survey estimates. Associated biases for heat and anthropogenic $\mathrm{CO}_{2}$ are shown in Figs. 9 and 10, respectively. The variability associated with this term is generally smaller than with the first component. Yet, in the Southern Ocean, this bias is large, reaching up to $40 \%$ of anthropogenic $\mathrm{CO}_{2}$ transport and even locally exceeding corresponding total meridional transport of heat. In the subtropics of all three basins, the bias is typically less than $0.12 \mathrm{PW}$ for heat transport and below $0.02 \mathrm{Pg} \mathrm{Cyr}^{-1}$ for anthropogenic $\mathrm{CO}_{2}$. At $25^{\circ} \mathrm{N}$ in the North Atlantic, the bias is less than $0.05 \mathrm{PW}$ for heat transport and around $0.004 \mathrm{PgC} \mathrm{yr}^{-1}$ for anthropogenic $\mathrm{CO}_{2}$, which represents about $5 \%$ of their respective annual-mean transports. In the North Pacific at $32^{\circ} \mathrm{N}$, this uncertainty is as large as $0.1 \mathrm{PW}$ for heat ( $40 \%$ of the annual-mean transport) and
$0.02 \mathrm{Pg} \mathrm{Cyr}^{-1}$ for anthropogenic $\mathrm{CO}_{2}$ (100\% of the annualmean transport). More details on uncertainties in the hydrographic transport estimates due to this second term, seasonal tracer variability, are provided in Table 1 for heat and Table 2 for anthropogenic $\mathrm{CO}_{2}$.

The third term in Eq. (4) concerns the variability of the eddy transport about the time-mean. Generally, biases associated with this term are very small except near the equator $\left(10^{\circ} \mathrm{S}-10^{\circ} \mathrm{N}\right)$ and in the Southern Ocean (Figs. 9 and 10). In the Pacific Ocean at $5^{\circ} \mathrm{N}$, this variability reaches $0.25 \mathrm{PW}$ for heat transport and $0.046 \mathrm{Pg} \mathrm{Cyr}^{-1}$ for anthropogenic $\mathrm{CO}_{2}$ transport. In the Southern Ocean, this eddy bias reaches $0.1 \mathrm{PW}$ for heat transport and $0.03 \mathrm{Pg} \mathrm{C} \mathrm{yr}^{-1}$ for anthropogenic $\mathrm{CO}_{2}$ transport, respectively. In the subtropics in all three basins, the variability associated with this term is quite small, i.e., $0.01-0.02 \mathrm{PW}$ for heat transport and less than $0.01 \mathrm{PgC} \mathrm{yr}^{-1}$ for anthropogenic $\mathrm{CO}_{2}$ transport. Therefore, the eddy variabilty appears to play a negligible role in the time dependence of the meridional tracer transport at these latitudes. Yet, this term is well known to strongly depend on the spatial resolution of sampling. Therefore, it might introduce a larger bias in the transport estimates if the sampling is done with an insufficient resolution. To test this hypothesis, we estimated this term using a 4 times coarser sampling, meaning an average resolution of $136 \mathrm{~km}$ instead of the original eddy-permitting model resolution of $34 \mathrm{~km}$. We found that the eddy temporal variabilty estimated with this coarser 136-km resolution is generally 2 to 3 times larger. In the North Atlantic, the eddy bias can represent up to $10 \%$ of the total transport of heat and up to $15 \%$ of the total 
transport of anthropogenic $\mathrm{CO}_{2}$. Thus proper sampling resolution is crucial for providing accurate hydrography-based transport estimates. The actual eddy bias may be much larger given that estimates here rely on a eddy permitting model that by definition does not resolve the full spectrum of even mesoscale eddies. Findings from this analysis are summarized in Tables 1 and 2.

\section{Summary and Conclusions}

We found that the seasonal cycle of the meridional transport of anthropogenic $\mathrm{CO}_{2}$ is similar to that for heat, with both having the largest amplitude confined to the tropics. Near the equator, the peak-to-peak amplitude of total annual cycle of meridional transport reaches between 6 and $8 \mathrm{PW}$ for heat and between 1.2 and $1.5 \mathrm{Pg} \mathrm{Cyr}^{-1}$ for anthropogenic $\mathrm{CO}_{2}$. In the subtropics, this seasonal variability ranges from 1.5 to $2 \mathrm{PW}$ for heat and between $0.4 \mathrm{PgC}^{-1}$ and $0.5 \mathrm{PgC}^{-1}$ for anthropogenic $\mathrm{CO}_{2}$. This variability is dominated by the Ekman transport except near the equator and at southern midlatitudes, where the contribution from the baroclinic component (due to vertical shear) also becomes important.

We also investigated the contribution of the mesoscale variability to the mean transport. Eddy rectification contributes to the meridional transport via large poleward transport of heat and anthropogenic $\mathrm{CO}_{2}$ associated with the ACC as well as substantial convergent transport about the equator, particularly in the Pacific Ocean and in the Indian Ocean around $15^{\circ} \mathrm{S}$. The comparison of our eddy-permitting simulations to additional runs performed at coarser resolution shows that most of the rectified eddy transport at mid and high latitudes results from mesoscale eddy activity, whereas near the equator, other processes that are insensitive to horizontal model resolution (e.g., variability in Ekman transport) also play some role.

Finally, we quantified the extent to which neglecting temporal variability could alter hydrography-based estimates of time-mean transports of heat and anthropogenic $\mathrm{CO}_{2}$. For both tracers, the largest bias introduced by such variability was found to be associated with the neglect of the nonEkman variability in those calculations. Near the equator, this bias is even larger than the annual-mean transport. In the subtropical North Atlantic, where most of the hydrographic surveys were conducted, the bias from neglecting the nonEkman transport of heat and anthropogenic $\mathrm{CO}_{2}$ can reach up to $20 \%$ and $30 \%$ of the respective annual-mean transports. In the subtropical South Atlantic seasonal variability represents up to $35 \%$ of the annual-mean transport of heat and $20 \%$ of the annual-mean transport of anthropogenic $\mathrm{CO}_{2}$. The other two additional sources of bias in synoptic survey estimates, due to seasonality of the tracer field and the eddy variability, are in general much smaller. Yet, for hydrographic surveys whose sampling resolution does not resolve the eddy field, the bias due to eddy variability becomes susbtantially larger and can represent in the North Atlantic up to $10 \%$ and $15 \%$ of total transports of heat and anthropogenic $\mathrm{CO}_{2}$ in the North Atlantic.

We have demonstrated that for reliable hydrography-based transport estimates of anthropogenic $\mathrm{CO}_{2}$ and heat, methods must properly account for non-Ekman seasonal variability. They also need to account for eddy variability which cannot be captured without fine-scale surveys. Errors due to temporal variabilty appear to be generally small in the Atlantic and the Indian subtropics, but in some of the most energetic regions, such as near the equator and at southern mid-latitudes, the bias can be much larger. These biases further call into question the approach of using hydrography-based transport estimates of anthropogenic $\mathrm{CO}_{2}$ to deduce regional air-sea $\mathrm{CO}_{2}$ fluxes.

Acknowledgements. We thank the ESOPA group at LOCEAN for the general support, improvements, and maintenance of the ocean model OPA-ORCA. We also thank B. Barnier, A.-M. Treguier, J.-M. Molines, G. Madec, and other members of the DRAKKAR project for discussions, particularly their expertise concerning the model configurations used here. Support for this research has come from the French Commissariat à l'Energie Atomique (CEA), the EU CARBOOCEAN Project (Contract no. 511176 [GOCE]) and the Swiss Federal Institute of Technology Zurich (ETH Zurich). Computations were performed at CEA (CCRT) supercomputing center.

Edited by: S. W. A. Naqvi

\section{References}

Álvarez, M., Lo Monaco, C., Tanhua, T., Yool, A., Oschlies, A., Bullister, J. L., Goyet, C., Metzl, N., Touratier, F., McDonagh, E., and Bryden, H. L.: Estimating the storage of anthropogenic carbon in the subtropical Indian Ocean: a comparison of five different approaches, Biogeosciences, 6, 681-703, 2009, http://www.biogeosciences.net/6/681/2009/.

Álvarez, M., Ríos, A. F., and Pérez, F. F.: Transports and budgets of total inorganic carbon in the subpolar and temperate North Atlantic, Global Biogeochem. Cy., 17(1), 1002, doi:10.1029/2002GB001881, 2003.

Berliand, M. E. and Strokina, T.: Global distribution of the total amount of clouds, Hydrometeorological Publishing House, Leningrad, Russia, 71 pp., 1980 (in Russian).

Blanke, B. and Delecluse, P.: Low frequency variability of the tropical Atlantic ocean simulated by a general circulation model with two different mixed layer physics, J. Phys. Oceanogr., 23, 13631388, 1993.

Böning, C. W. and Cox, M. D.: Particle dispersion and mixing of conservative properties in an eddy-resolving model, J. Phys. Oceanogr., 18, 320-338, 1988.

Böning, C. W. and Herrmann, P.: Annual cycle of poleward heat transport in the ocean: results from high-resolution modeling of the North and Equatorial Atlantic, J. Phys. Oceanogr., 24(1), 91107, 1994.

Böning, C. W., Dieterich, C., Barnier, B., and Jia, Y.: Seasonal cycle of meridional heat transport in the subtropical North Atlantic: a model intercomparison in relation to observations near $25^{\circ} \mathrm{N}$, Prog. Oceanogr., 48(2-3), 231-253, 2001. 
Brewer, P., Goyet, C., and Dyrssen, D.: Carbon dioxide transport by ocean currents at $25 \mathrm{n}$ latitude in the Atlantic Ocean, Science, 246, 477-479, 1989.

Bryan, K.: Seasonal variation in meridional overturning and poleward heat transport in the atlantic and pacific oceans: A model study, J. Mar. Res., 40, suppl., 39-53, 1982.

Bryden, H. L.: Poleward heat flux and conversion of available potential energy in Drake Passage, J. Mar. Res., 37, 1-22, 1979.

Bryden, H. L. and Brady, E. C.: Eddy momentum and heat fluxes and their effects on the circulation of the equatorial Pacific Ocean, J. Mar. Res., 47, 55-79, 1989.

Bryden, H. L. and Hall, M. M.: Heat transport by ocean currents across $24^{\circ} \mathrm{N}$ latitude in the atlantic, Science, 207, 884-886, 1980.

Bryden, H. L. and Heath, R. A.: Energetic eddies at the northern edge of the Antarctic Circumpolar Current in the Southest Pacific, Prog. Oceanogr., 14, 65-87, 1985.

Carissimo, B. C., Oort, A. H., and Haar, T. H. V.: Estimating the meridional energy transports in the atmosphere and ocean, J. Phys. Oceanogr., 15, 82-91, 1985.

Cessi, P. and Fantin, M.: The eddy-driven thermocline, J. Phys. Oceanogr., 34(12), 2642-2658, 2004.

Cox, M.: Isopycnal diffusion in a z-coordinate ocean model, Ocean Model., 74, 1-9, 1987.

de Szoeke, R. A. and Levine, M. D.: The advective flux of heat by mean geostrophic motions in the Southern Ocean, Deep-Sea Res., 28, 1057-1084, 1981.

Doney, S. and Bullister, J.: A chlorofluorocarbon section in the eastern north atlantic, Deep-Sea Res., 39, 1857-1883, 1992.

Dutay, J.-C., Bullister, J., Doney, S. C., Orr, J. C., Najjar, R. G., Caldeira, K., Campin, J.-M., Drange, H., Follows, M., Gao, Y., Gruber, N., Hecht, M. W., Ishida, A., Joos, F., Lindsay, K., Madec, G., Maier-Reimer, E., Marshall, J. C., Matear, R., Monfray, P., Mouchet, A., Plattner, G. K., Sarmiento, J. L., Schlitzer, R., Slater, R. D., Totterdell, I. J., Weirig, M.-F., Yamanaka, Y., and Yool, A.: Evaluation of ocean model ventilation with CFC11: Comparison of 13 global ocean models, Ocean Model., 4, 89-120, 2002.

England, M. H., Garcon, V., and Minster, J. F.: Chlorofluorocarbon uptake in a world ocean model. 1. sensitivity to the surface gas forcing, J. Geophys. Res., 99(C12), 25 215-25 234, 1994.

Fichefet, T. and Maqueda, M. M.: Sensitivity of a global sea ice model to the treatment of ice thermodynamics and dynamics, J. Geophys. Res., 102, 12 609-12 646, 1997.

Ganachaud, A. and Wunsch, C.: Improved estimates of global ocean circulation, heat transport and mixing from hydrographic data, Nature, 408, 453-457, 2000.

Ganachaud, A. and Wunsch, C.: Oceanic nutrient and oxygen transports and bounds on export production during the World Ocean Circulation Experiment, Global Biogeochem. Cy., 16, 1057, doi:10.1029/2000GB001333, 2002.

Ganachaud, A.: Large-scale mass transports, water mass formation, and diffusivities estimated from World Ocean Circulation Experiment (WOCE) hydrographic data, J. Geophys. Res., 108(C7), 3213, doi:10.1029/2002JC001565, 2003.

Garternicht, U. and Schott, F.: Heat fluxes of the indian ocean from a global eddy-resolving model, J. Geophys. Res., 102(C9), 21 147-21 159, 1997.

Gaspar, P., Gregorius, Y., and Lefevre, J. M.: A simple eddy kinetic energy model for simulation of oceanic vertical mixing tests at Station Papa and Long-Term Upper Ocean Study Site, J. Geophys. Res., 95, 16 179-16 193, 1990.

Gent, P. R., Bryan, F. O., Danabasoglu, G., Doney, S. C., Holland, W. R., Large, W. G., and McWilliams, J. C.: The ncar climate system model global ocean component, J. Climate, 11, 12871306, 1998.

Goose, H.: Modeling the large scale behaviour of the coupled ocean-sea ice system, Ph.D. thesis, Université Catholique de Louvain, Louvain-la-Neuve, Belgium, 1997.

Hall, M. M. and Bryden, H. L.: Direct estimates and mechanisms of ocean heat transport, Deep-Sea Res., 29, 339-359, 1982.

Holfort, J., Johnson, K. M., Scheider, B., Siedler, G., and Wallace, D. W. R: Meridional transport of dissolved inorganic carbon in the South Atlantic Ocean, Global Biogeochem. Cy., 12, 479499, 1998.

Ishida, A., Sasai, Y., and Yamanaka, Y.: Role of Eddies in Chlorofluorocarbon Transport in Wind-Driven Oceanic Layers, J. Phys. Oceanogr., 37, 2491-2508, 2007.

Jakobsson, M., Cherkis, N., Woodward, J., Coakley, B., and Macnab, R.: A new grid of Arctic bathymetry: A significant resource for scientists and mapmakers, Eos T. Am. Geophys Un., 81(9), p. 89 , p. 93 , p. $96,2000$.

Jayne, S. R. and Marotzke, J.: The dynamics of ocean heat transport variability, Rev. Geophys., 39, 385-411, 2001.

Jayne, S. R. and Marotzke, J.: The oceanic eddy heat transport, J. Phys. Oceanogr., 32, 3328-3345, 2002.

Kalnay, E., Kanamitsu, M., Kistler, R., Collins, W., Deaven, D., Gandin, L., Iredell, M., Saha, S., White, G., Woollen, J., Zhu, Y., Chelliah, M., Ebisuzaki, W., Higgins, W., Janowiak, J., Mo, K. C., Ropelewski, C., Wang, J., Leetma, A., Reynolds, R., Jenne, R., and Joseph, D.: The NCEP/NCAR 40-year reanalysis project, B. Am. Meteorol. Soc., 77, 437-471, 1996.

Key, R. M., Lee, C. L. S. K., Wanninkhof, R., Bullister, J., Feely, R. A., Millero, F. J., Mordy, C., and Peng, T.-H.: A Global Ocean Carbon Climatology: Results from Global Data Analysis Project (GLODAP), Global Biogeochem. Cy., 18, GB4031, doi:10.1029/2004GB002247, 2004.

LaCasce, J. H. and Pedlosky, J.: The instability of rossby basin modes and the oceanic eddy field, J. Phys. Oceanogr., 34, $2027-$ 2041, 2004.

Lachkar, Z., Orr, J. C., Dutay, J.-C., and Delecluse, P.: Effects of mesoscale eddies on global ocean distributions of CFC-11, $\mathrm{CO}_{2}$ and $\delta^{14} \mathrm{C}$, Ocean Sci., 3, 461-482, 2007,

http://www.ocean-sci.net/3/461/2007/.

Lachkar, Z., Orr, J. C., Dutay, J. C., and Delecluse, P.: On the role of mesoscale eddies in the ventilation of Antarctic intermediate water, Deep-Sea Res. Pt. I, 56(6), 909-925, doi:10.1016/j.dsr.2009.01.013, 2009.

Large, W. G., Danabasoglu, G., Doney, S. C., and McWilliams, J. C.: A review and a model with a non-local boundary layer parameterization, Rev. Geophys., 32, 363-403, 1997.

Lavin, A., Bryden, H. L., and Parrilla, G.: Mechanisms of heat, freshwater, oxygen and nutrient transports and budgets at $24.5 \mathrm{n}$ in the subtropical North Atlantic, Deep Sea Res. Pt. I, 50, 10991128, 2003.

Lee, T. and Marotzke, J.: Inferring meridional mass and heat transports of the Indian Ocean by fitting a GCM to climatological data, J. Geophys. Res., 102, 10 585-10 602, 1997. 
Lee, T. and Marotzke, J.: Seasonal cycle of meridional overturning and heat transport of the Indian Ocean, J. Phys. Oceanogr., 28, 923-943, 1998.

Levitus, S., Boyer, T. P., Conkright, M. E., O’Brian, T., Antonov, J., Stephens, C., Stathopolos, L., Johnson, D., and Gelfeld, R.: World Ocean Database 1998: Vol. 1: Introduction, NOAA Atlas NESDID 18, US Government Printing Office, Washington, DC, 346 pp., 1998.

Lythe, M. and Vaughan, D.: BEDMAP: a new ice thickness and subglacial topograpic model of Antarctica, J. Geophys. Res., 106, $11335-11351,2001$.

Macdonald, A. M. and Wunsch, C.: An estimate of the global ocean circulation and heat flux, Nature, 382, 436-439, 1996.

Madec, G., Delecluse, P., Imbard, M., and Levy, C.: OPA version 8.1 Ocean General Circulation Model Reference Manual, Note du pole de modelisation, 11, IPSL, France, 91 pp., 1998.

Madec, G. and Imbard, M.: A global ocean mesh to overcome the North Pole singularity, Clim. Dynam., 12, 381-388, 1996.

Marshall, J., Olbers, D., Ross, H., and Wolf-Gladrow, D.: Potential vorticity constraints on the dynamics and hydrography of the southern ocean, J. Phys. Oceanogr., 23, 465-487, 1993.

Martel, F. and Wunsch, C.: The North Atlantic circulation in the early 1980s: An estimate from inversion of a finite difference model, J. Phys. Oceanogr., 29, 283-383, 1993.

Matsumoto, K. and Gruber, N.: How accurate is the estimation of anthropogenic carbon in the ocean?, An evaluation of the DC* method, Global Biogeochem. Cy., 19, GB3014, doi:10.1029/2004GB002397, 2005.

Orr, J. C., Monfray, P., Maier-Reimer, E., Mikolajewicz, U., Palmer, J., Taylor, N. K., Toggweiler, J. R., Sarmiento, J. L., Quéré, C. L., Gruber, N., Sabine, C. L., Key, R. M., and Boutin, J.: Estimates of anthropogenic carbon uptake from four three-dimensionsal global ocean models, Global Biogeochem. Cy., 15, 43-60, 2001.

Orsi, A. H., Johnson, G. C., and Bullister, J. L.: Circulation, mixing, and production of Antarctic Bottom Water, Prog. Oceanogr., 43, 55-109, 1999.

Philander, S. G. H. and Delecluse, P.: Coastal currents in low latitudes, Deep-Sea Res., 30, 887-902, 1983.

Philander, S. G. H. and Pacanowski, R. C.: The mass and heat budget in a model of the tropical Atlantic Ocean, J. Geophys. Res., 91(C12), 14212-14 220, 1986.

Qiao, L. and Weisberg, R. H.: Tropical instability wave energetics: Observations from the Tropical Instability Wave Experiment, J. Phys. Oceanogr., 28, 345-360, 1998.

Qiu, B. and Chen, S.: Seasonal modulations in the eddy field of the south pacific ocean, J. Phys. Oceanogr., 34, 1515-1527, 2004.

Rintoul, S. R. and Wunsch, C.: Mass, heat, oxygen and nutrient fluxes and budgets in the North Atlantic Ocean, Deep-Sea Res., 38, 355-377, 1991.

Roemmich, D. and Wunsch, C.: Two transatlantic sections: meridional circulation and heat flux in the subtropical North Atlantic Ocean, Deep-Sea Res., 32, 619-664, 1985.

Sarmiento, J. L., Orr, J. C., and Siegenthaler, U.: A perturbation simulation of $\mathrm{CO}_{2}$ uptake in an ocean general circulation model, J. Geophys. Res., 97, 3621-3645, 1992.

Schopf, P. S.: The role of Ekman flow and planetary waves in the oceanic cross-equatorial heat transport, J. Phys. Oceanogr., 10, 330-341, 1980.
Siegenthaler, U. and Joos, F.: Use of a simple model for studying oceanic tracer distributions and the global carbon cycle, Tellus B, 44, 186-207, 1992.

Smith, W. H. F. and Sandwell, D. T.: Global seafloor topography from satellite altimetry and ship depth soundings, Science, 277, 1957-1962, 1997.

Stammer, D.: On eddy characteristics, eddy transports, and mean flow properties, J. Phys. Oceanogr., 28, 727-739, 1998.

Steele, M., Morley, R., and Ermold, W.: PHC: A global ocean hydrography with a high quality Arctic Ocean, J. Climate, 14, 2079-2087, 2001.

Talley, L. D, Reid, J. L, and Robbins, P. E: Data-Based Meridional Overturning Streamfunctions for the Global Ocean, J. Climate, 16, 3213-3226, 2003.

Thompson, S. R.: Estimation of the transport of heat in the southern ocean using a fine resolution numerical model, J. Phys. Oceanogr., 23, 2493-2497, 1993.

Trenberth, K. E., Olson, J. G., and Large, W. G.: A global ocean wind stress climatology based on ECMWF analyses, Report NCAR/TN-338 +STR, National Center for Atmos. Res., Boulder, Colorado, 93 pp., 1989.

Vázquez-Rodríguez, M., Touratier, F., Lo Monaco, C., Waugh, D. W., Padin, X. A., Bellerby, R. G. J., Goyet, C., Metzl, N., Ríos, A. F., and Pérez, F. F.: Anthropogenic carbon distributions in the Atlantic Ocean: data-based estimates from the Arctic to the Antarctic, Biogeosciences, 6, 439-451, 2009, http://www.biogeosciences.net/6/439/2009/.

Volkov, D. L., Lee, T., Fu, L. L., and Godfrey, J.: Eddy-induced meridional heat transport in the ocean, Geophys. Res. Lett., 35, L20601, doi:10.1029/2008GL035490, 2008.

Wacongne, S. and Pacanowski, R.: Seasonal heat transport in a primitive equations model of the tropical indian ocean, J. Phys. Oceanogr., 26(12), 2666-2699, 1996.

Wallace, D. and Lazier, J.: Anthropogenic chlorofluoromethanes in newly formed labrador sea water, Nature, 332, 61-63, 1988.

Wallace, D. W. R.:Storage and transport of excess $\mathrm{CO}_{2}$ in the Oceans: The JGOFS/WOCE Global $\mathrm{CO}_{2}$ Survey, in: Ocean Circulation and Climate, Academic, San Diego, Calif., 489-520, 2001.

Waugh, D. W., Hall, T. M., McNeil, B. I., Key, R., and Matear, R. J.: Antropogenic $\mathrm{CO}_{2}$ in the oceans estimated using transit time distributions, Tellus B, 58(5), 376-389, 2006.

Wilkin, J., Mansbridge, J., and Godfrey, J.: Pacific Ocean heat transport at $24 \mathrm{~N}$ in a high-resolution global model, J. Phys. Oceanogr., 25, 2204-2214, 1995.

Willebrand, J., Philander, S. G. H., and Pacanowski R. C.: The oceanic response to large-scale atmospheric disturbances, J. Phys. Oceanogr., 10, 411-429, 1980.

Wunsch, C.: The north atlantic general circulation west of $50^{\circ} \mathrm{W}$ determined by an inverse method, Rev. Geophys. Space Phys., 16(4), 583-620, 1978.

Wunsch, C.: Where do ocean eddy heat fluxes matter, J. Geophys. Res., 104, 13 235-13 249, 1999.

Xie, P. and Arkin, P. A.: Analyses of global monthly precipitation using gauge observations, satellite estimates and numerical model predictions, J. Climate, 9, 840-858, 1996. 